\title{
Modelling of Distributed Business Processes
}

\author{
H. Grabowski, and Torsten Engel \\ Research Center for information technologies at the University of Karlsruhe, pde@fzi.de
}

\begin{abstract}
Today enterprises face the challenge to participate in enterprise networks. Business processes in these networks extend well beyond enterprise boundaries. Definition and optimisation of business processes requires adequate modelling languages, which support the modelling of cross-organizational information and material flows. This paper discusses innovative concepts, which extend existing modelling language concepts for these new requirements.
\end{abstract}

\section{INTRODUCTION: NEW ORGANIZATIONAL FORMS}

Today enterprises face dramatic changes: Internationalisation of market and competition relations, increasing complexity of products and services, shorter life cycles and individualisation of market and client requirements, dynamic changes and innovations of processes and organizational structures etc. These changes require that in the future more business partners must contribute to the value chain. New forms of collaboration over enterprise boundaries have to be developed and set up (Gora, Scheid, 2001). By leaving enterprise boundaries risk sharing, reduction of complexity and bundling of task-specific competencies can be used in a wider range (Specht, Kahmann, 2000). Two general organizational forms have been developed in the last years: the virtual corporation and the extended enterprise.

These modern organizational forms require a more detailed and usually short-term inter-organizational information exchange. In this context business-process models can decisively support the decision making in two ways: First, to bring potential partners together and second to form the business processes of the common enterprise in an optimal way (Kosanke, Zelm, 
2002). But cross-organizational business processes, the distributed business processes, can nowadays only be modelled in an insufficient way.

\section{STATUS QUO}

According to DAVIDOW and MALONE (quoted in Brütsch, 1999), "the virtual corporation is a temporary network of independent companies, suppliers, customers even erstwhile rivals - linked by information technology to share skills, costs and access to one another's markets". A virtual corporation is usually created from corporate networks for a specific business task. An inter-enterprise networking across the value chain is usually termed an extended enterprise. The business in an extended enterprise is linked back through the supplier chain and forward into the distribution and customer chain (Brown, Zhang, 1999).

Both have in common that they imply crossing-boundary business activities. These organizational forms are the basis for an optimal configuration of business processes and they present the chance to optimise the value-chain across company boundaries (Brütsch, 1999). The efficient implementation of distributed business processes across several companies requires a best possible support by information systems. Various innovative concepts are developed from different vendors and research organisations to support the collaboration of companies and their different information systems at different locations. But they often focus on technical solutions like data transfer and they neglect the optimisation of the distributed business processes, which are integrated within the information systems.

Distributed business processes have to be continuously analysed and optimised during the evolution of a virtual organisation in order to maximally benefit from the collaboration. A prerequisite for an optimisation and realisation of distributed business processes is a common understanding and clear definition of the processes within the virtual organisation. Tools and methods of enterprise modelling have proved success for the analysis and optimisation of business processes in an individual company (Grabowski, Adamietz, 1998). But traditional enterprise modelling focused on business processes and organizational structures within an isolated company. Collaboration with other companies was merely described as information and material flow from and to other, usually unspecified companies. Optimisation across company boundaries requires an extended view on business processes: Business processes in virtual companies or extended enterprises can influence the work of several companies. Several aspects of business process analysis and modelling must be extended to support the concepts of virtual corporations and extended enterprises: 
- Analysis methodology: Methodologies must be extended to integrate all companies participating in a virtual corporation or an extended enterprise in a consistent way.

- Modelling language: Modelling languages must semantically and syntactically support the modelling of distributed business processes.

- Modelling tools: Tools should support concurrent modelling.

In the EC-funded project BURMA-X (Business Relationship Management for the extended enterprise) (BURMA_X, http://) a new approach for analysing extended enterprises was developed. This approach integrates the analysis of cross-organizational aspects of an extended enterprise and also the consequences for the individual companies.

Many existing modelling tools often already support concurrent modelling. Often the tools were extended to client-server-applications with a central database, but the used modelling language usually was not adapted to the requirements of modelling distributed business processes. Following the requirements for a modelling language to make documentation and improvement of distributed business processes possible for modellers and users are discussed.

\section{REQUIREMENTS FOR MODELING DISTRIBUTED BUSINESS PROCESSES}

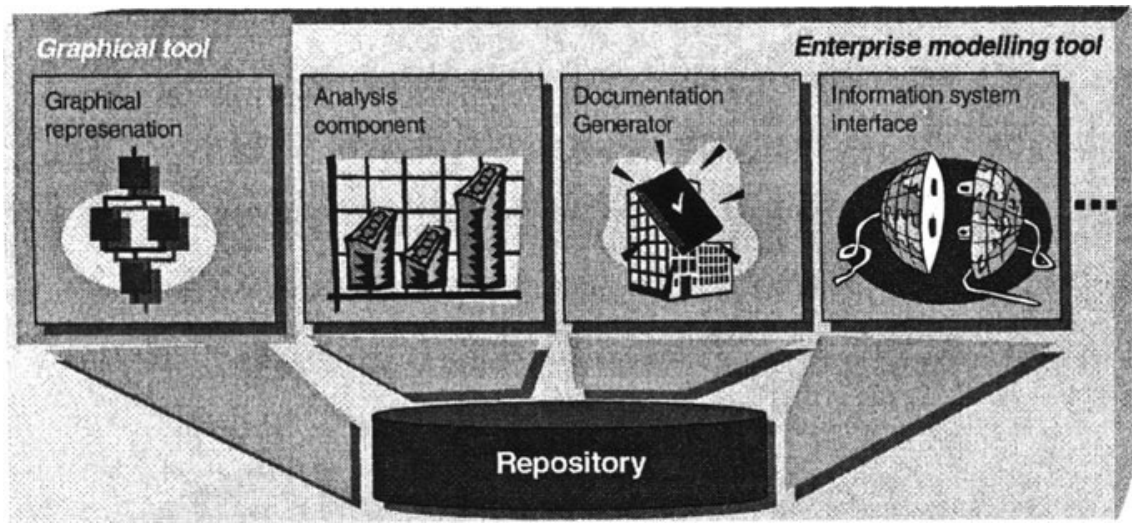

Figure 1: Advantages of an enterprise modeling tool

In contrast to graphical tools modelling tools have the decisive advantage of having the enterprise model in a repository. This allows to graphically displaying the model for further usage of the model for analysis, automated documentation, model-based adaptation of information systems etc. (Fig. 1). But current modelling tools very seldom offer the possibility to model cross- 
organizational aspects in a graphical way. If, they usually are not representing the model semantic in the repository.

An example for a typical, important aspect in modelling crossorganizational business processes is to identify the change of responsibility in a process. A widespread way to show this graphically is to place activityconstructs in columns ("swim lanes") representing a company (Fig. 2). An analysis or evaluation of the change of responsibility further requires, that the company-specific responsibility be also represented in the enterprise model repository.

Fig. 2 shows an extract from a distributed business process. An analysis of the number of changes of responsibility in this example can only be done if the companies "Deliverer", "Company X" and "Client" are represented in the modelling language as actual enterprise objects assigned to the relevant activities and not as simple graphical elements of a view.

The decisive difference between enterprise models for individual companies and enterprise models for virtual or extended enterprises is the coexistence of company-

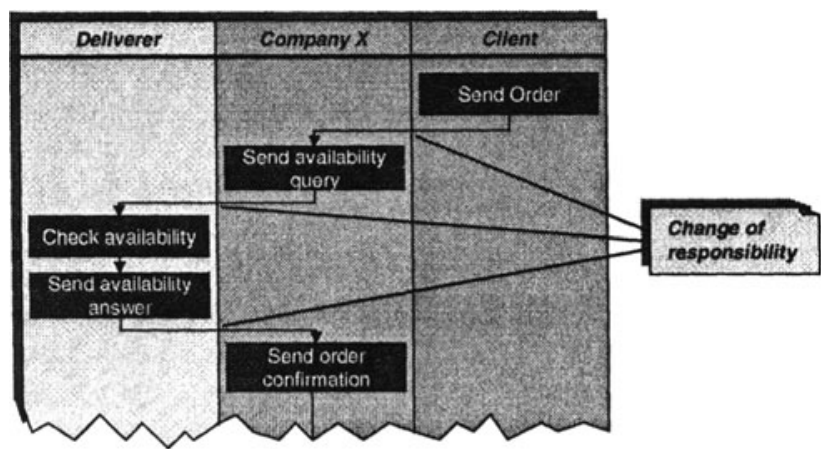

Figure 2: Example for graphical representation of change of resnonsibilitv within a distributed business nrocess neutral and company-specific modelling constructs. An enterprise modelling language for virtual organisations therefore has to offer the additional possibility to assign relevant enterprise objects to a certain company represented in the model.

\section{BASIC CONCEPTS}

In the course of the BURMA-X project mentioned above an Internet portal for the operation of extended enterprises is developed in order to facilitate development and production across company boundaries, provision of highlevel after sales services, even if components have been produced by partners and by definition and easy execution of cross-organizational business processes. The communication platform integrates various services like cross-organizational product catalogues, stock control, knowledge manage- 
ment, contact search etc. that can be easily and quickly integrated (Fig. 3). In the same way new companies can easily be integrated into or replaced from the portal. A first prototype of the portal will be presented in summer 2002.

The portal development is based on a business process analysis of an existing extended enterprise within the BURMA-X consortium. In the course of the project the MERGE method and toolkit, which were developed at the research centre for information technologies (FZI, http://), were used. The MERGE method was adapted to the requirements of extended business processes analysis (Grabowski, Engel, 2002). Further, a first prototype of an extended version of the MERGE-Toolkit was used, which allows modelling of extended business processes. In this context the following basic concepts for an extended business processes modelling language were determined.

As mentioned above enterprise models for virtual companies or extended enterprises should offer the possibility to assign enterprise objects to certain

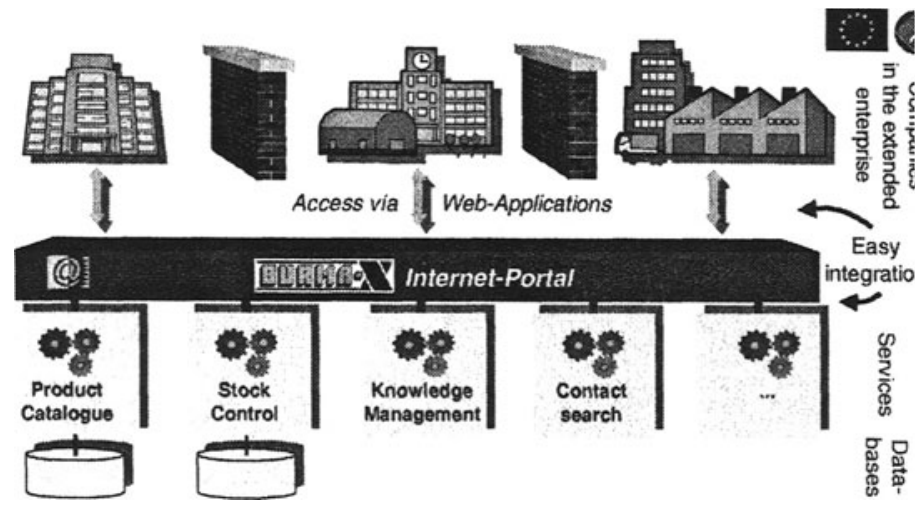

Figure 3: Architecture of the BURMA-X internet portal for extended enterprises

companies. The basic prerequisite to model company-specific enterprise objects is the existence of an enterprise object class company. If an enterprise object in a model is connected to an enterprise object of the class company, it is identified as a specific object for this company. The responsibility of a company for a certain activity in a business process can now be modelled by assigning the activity to the company.

But an assignment of an activity to a company is often not detailed enough. The responsible organisation unit or situation in the company is also important both for internal co-ordination and to make the relevant contact clear to business partners (Kugeler, 2002). For that reason a modelling language should offer the possibility to model the organizational structure of a company and to assign an organizational unit of a certain company to an enterprise object in order to identify enterprise specific objects. Fig. 4 shows an extract of an organizational structure diagram created with the mentioned MERGE-Toolkit prototype. 


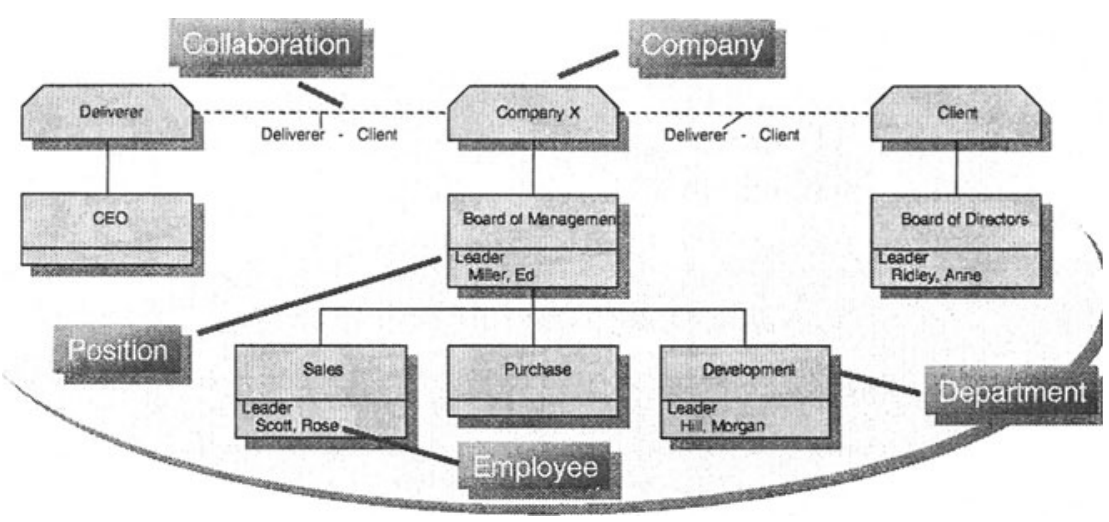

Figure 4: Example of an extended enterprise structure modeled with Merge

Typical examples for company-specific enterprise objects are:

- Activities: As mentioned above company-specific activities show the responsibility of a company to perform this action in a process. Further it is possible to identify at which points in a process companies have to exchange data and/or material respectively where they have to collaborate.

- Resources: As collaboration between companies is often involved with collaboration of information systems or resources in general, relevant resources should not only be identified but also assigned to the company, which is the owner of the resource.

- Data objects: The information exchange between companies requires the definition of data objects, which are to be exchanged. The data objects are the basis to model the information flow between the companies: Which data does a company send to a partner?

The last aspect, the cross-organizational data modelling, has a strong impact on connecting different information systems (Kugeler, 2002). In different companies data objects can have the same semantic meaning, but different attributes and data formats. Mapping of different data structures is an important aspect to enable collaborating companies to exchange data electronically. If two companies collaborate e.g. as client and supplier, the client will send orders to the supplier. The IT-systems of both companies will store data for orders. But they will use different formats or they will even store different data concerning an order. So the modelling of extended business processes requires transparency concerning

- The differentiation of equal data objects with different formats and

- The transformation between the formats within the processes. 


\section{SUMMARY AND OUTLOOK}

Modern organizational forms like virtual or extended enterprises require an extended way of modelling business processes. Current modelling tools respectively languages do not fulfil these requirements. New modelling constructs are necessary to identify company-specific elements in a crosscompany enterprise model.

The growing importance of concepts for cross-company information systems like EAI (Enterprise Application Integration) or SCM (Supply Chain Management) will increase the demand for modelling distributed business processes in the future. Virtual or extended enterprises will need an efficient way to co-ordinate the co-operation of the participating companies. Extended business-process models combine the experience of traditional business process modelling with special features for modelling the business processes of these new organizational forms.

\section{REFERENCES}

Browne, J. Zhang, J. (1999), Extended and virtual enterprises - similarities and differences, in: International Journal of Agile Management Systems 1/1, MCB University Press

Brütsch, D. (1999), Virtuelle Unternehmen, Zürich: vdf, Hochschulverlag AG an der ETH Zürich

BURMA-X, http://www.burma-X.de

FZI, http://www.fzi.de/pde

Gora, W.; Scheid, E.: (2001), Organisation auf dem Weg zur Virtualität, in: Gora, W.; Bauer, H.: „Virtuelle Organisationen im Zeitalter von E-Business und E-Government“, SpringerVerlag

Grabowski, H. Adamietz, P. (1998), Prozeßorientiertes Customizing von EDM/PDMSystemen, in: Informationsverarbeitung in der Konstruktion '98 - Prozeßketten für die virtuelle Produktentwicklung in verteilter Umgebung; Düsseldorf: VDI-Verlag

Grabowski, H., Engel T. (2002), Business Process Analysis in Virtual Organisations, in: Proceedings PDTEurope 2002; Sandhurst: Quality Marketing Services, 2002

Kosanke, K.; Zelm, M.: (2002), Geschäftsprozeßmodelle für Wissensmanagement und Entscheidungsunterstützung, in: Industrie Management 1/2002; Berlin: Gito-Verlag

Kugeler, M. (2002), Supply Chain Management und Customer Relationship Management Prozessmodellierung für Extended Enterprises, in: Becker, J.; Kugeler, M.; Rosemann, M. (Hrsg.): Prozessmanagement: Ein Leitfaden zur prozessorientierten Organisationsgestaltung; Berlin: Springer-Verlag

Specht, D.; Kahmann, J. (2000), Regelung kooperativer Tätigkeit im virtuellen Unternehmen, in: Albach, H.; Specht, D.; Wildemann, H.: Virtuelle Unternehmen, Wiesbaden: Gabler 